Research Article

\title{
Investigating the Relationship of Test Anxiety and Time Management with Academic Procrastination in Students of Health Professions
}

\author{
Sarvenaz Roshanisefat, ${ }^{1}$ Seyyed Mohsen Azizi $\left(\mathbb{D},{ }^{2}\right.$ and Alireza Khatony $\mathbb{D}^{3,4}$ \\ ${ }^{1}$ Student Research Committee, Kermanshah University of Medical Sciences, Kermanshah, Iran \\ ${ }^{2}$ Clinical Research Development Center, Imam Reza Hospital, Kermanshah University of Medical Sciences, Kermanshah, Iran \\ ${ }^{3}$ Social Development and Health Promotion Research Center, Health Institute, Kermanshah University of Medical Sciences, \\ Kermanshah, Iran \\ ${ }^{4}$ Infectious Diseases Research Center, Kermanshah University of Medical Sciences, Kermanshah, Iran
}

Correspondence should be addressed to Alireza Khatony; akhatony@gmail.com

Received 25 May 2021; Accepted 22 September 2021; Published 30 September 2021

Academic Editor: Michael Loughlin

Copyright (C) 2021 Sarvenaz Roshanisefat et al. This is an open access article distributed under the Creative Commons Attribution License, which permits unrestricted use, distribution, and reproduction in any medium, provided the original work is properly cited.

\begin{abstract}
Academic procrastination is a harmful phenomenon among students and has many negative consequences. The present study aimed to investigate the relationship of test anxiety and time management with academic procrastination in students of health professions. The population of this correlational study consisted of 281 Iranian students of health professions. The Tuckman Procrastination Scale, Time Management Scale, and Sarason's Test Anxiety Scale were used to measure the variables. Pearson's correlation and multivariate regression tests were also performed. The mean score of students' academic procrastination was higher than the average level. A significantly negative correlation was found between time management and academic procrastination $(r=-0.487, P \leq 0.01)$. Additionally, there was a significantly positive correlation between test anxiety and academic procrastination $(r=0.443, P \leq 0.01)$. The linear regression model indicated that independent predictors including time management and test anxiety accounted for $32.6 \%$ of the variation in academic procrastination $\left(R^{2}=32.6 \%\right)$. The findings of this study indicated that test anxiety and time management were associated with academic procrastination. Therefore, purposeful educational and psychological interventions are required to reduce academic procrastination in students.
\end{abstract}

\section{Introduction}

Recent studies have shown that procrastination is one of the most important challenges for students in universities and higher-education institutions [1-6]. Some researchers have reported a prevalence rate of $14-50 \%$ for procrastination among students [7, 8]. Procrastination is defined as "the students' delay in doing their homework or making a decision to act" $[9,10]$. Procrastination includes delays in doing course assignments, writing articles, and preparation for exam. Procrastination has a negative effect on individuals' quality of performance and mental-physical health [11]. Studies have illustrated that the most important characteristics of students who procrastinate are poor academic performance [12], low satisfaction with academic life [13], high stress [14], poor well-being, poor time management, misconceptions about the learning and teaching process [6], low marks in exams, and poor self-regulation [15]. In addition, one of the variables with a key role in increasing procrastination is anxiety [16]. Test anxiety is also a common type of anxiety among students, which is measured using the Sarason's Test Anxiety Scale [17, 18]. This variable has a negative effect on students' readiness for exams. In this regard, the results of one study showed a significant correlation between test anxiety and academic procrastination [19]. Another study, however, indicated a negative correlation between test anxiety and academic performance [18]. In addition, test anxiety reduces subjective well-being [20]. 
According to studies, time management is a vital skill for university students [21, 22]. Psychological studies have emphasized that people's ability in time management is rooted in their psychological and behavioral characteristics. Understanding the value of time, the ability to control time, and the optimal use of time are the most important characteristics of students with desirable time management skills $[23,24]$. Effective time management and optimal use of time involve planning, goal setting, and prioritizing activities in work and life [25]. According to the results of one study, time management training has a positive effect on reducing anxiety and depression and increasing sleep quality [24]. Other studies have shown that time management has a significantly positive correlation with academic motivation [25] and academic engagement [26]. Furthermore, time management has a significantly negative correlation with anxiety [25]. Therefore, it is important to identify its relationship with academic procrastination. Students of health professions are highly responsible for the health of the community. Therefore, the prevalence of procrastination among them has many negative consequences [27, 28]. Studies emphasize that procrastination in academic activities should be seriously considered $[1,29]$. Evidence suggests that students with academic procrastination fail to achieve academic goals [30] and have low levels of self-confidence [15]. In this regard, it is important to identify the factors associated with academic procrastination. Thus, the main purpose of this study was to investigate the correlation of test anxiety and time management with academic procrastination among students of health professions in Iran. To this end, the following questions were posed:

(1) Is there any significant relationship between test anxiety and time management and academic procrastination?

(2) To what extent do test anxiety and time management (independent variables) predict students' academic procrastination (dependent variable)?

\section{Methods}

2.1. Study Design. This was a cross-sectional descriptiveanalytical study.

2.2. Setting, Sample, and Sampling Method. The present study was conducted in the schools affiliated with the Kermanshah University of Medical Sciences (KUMS) in western Iran in 2020. The schools included nursing and midwifery, paramedical, health, pharmacy, dentistry, nutrition, and medicine. The sample size was calculated to be 281 students. The samples were selected by the stratified random sampling method, and each school formed a stratum. Inside each stratum, samples were selected by simple random sampling using a random number table. The response rate to the questionnaires was $100 \%$. The inclusion criteria were studying in the second semester or above and students' informed consent to participation in the study. The exclusion criterion was reluctance to answer the questionnaire.
2.3. Instruments. The tools used in this study included the demographic information form, Tuckman's Procrastination Scale, Time Management Scale, and Sarason's Test Anxiety Scale.

The demographic information form included questions about gender, age, marital status, and school.

Tuckman's Procrastination Scale (TPS) was designed by Tuckman (1991) [31]. This questionnaire consists of 16 items and has a single-factor structure. The validity and reliability of the English version of this scale have been confirmed by Tuckman [31, 32]. TPS has been validated in Iran, and its single-factor structure has been confirmed [33]. Other studies have reported optimal levels for the validity and reliability of this scale [4]. In the present study, the internal consistency of this scale was calculated using Cronbach's alpha at the 0.89 level. Each item was rated on a 5-point Likert scale, ranging from strongly disagree [1] to strongly agree [5]. The score range was from 16 to 64 . A high score indicated the student's academic procrastination.

The Time Management Scale (TMS) was designed by Trueman and Hartley and consists of 14 items [34]. This tool includes two subscales: daily planning (5 items) and confidence in long-term planning ( 9 items). In the study by Trueman and Hartley's, the reliability of the scale was 0.79 [34]. The validity and reliability of the Persian version of TMS have been confirmed as well [35]. In this study, Cronbach's alpha coefficient was calculated to be 0.77 . Each item is answered on a 5-point Likert scale $(1=$ never and 5 = always). The total score ranged from 14 to 70 . High scores indicate the student's top time management skills.

Sarason's Test Anxiety Scale (STAS) was developed by Sarason [36] and consists of 37 items. Raju et al. calculated the reliability of STAS to be 0.84 using Cronbach's alpha [37]. The validity and reliability of this scale in Iran have been confirmed at an acceptable level $[37,38]$. In the present study, Cronbach's alpha coefficient of the STAS was 0.78. A score of 0 was used for false answers, and a score of 1 was determined for correct answers. Total scores ranged from 0 to 37. The scores are categorized into three levels, including low anxiety (0-12), moderate anxiety (13-20), and high anxiety (21-37).

2.4. Data Collection Method. After the beginning of the academic year, the permission to conduct the research was obtained from the national ethics committee of KUMS (IR.KUMS.REC.1397.1049.). A statistical sample was determined, and the researchers attended the schools of KUMS. The students were explained about the objectives of the study and were asked to fill out the questionnaire. The students who were willing to participate in the research were included in the study. The questionnaires were distributed randomly and collected after completion.

2.5. Statistical Analysis. Data were analyzed by IBM SPSS- 18 software. Descriptive statistics (frequency, percentage, mean, and standard deviation) were used to identify the characteristics of the participants and to determine the means of the variables. Pearson's correlation coefficient and 
multivariate regression analysis were used to analyze the study questions. The level of significance was set at $P \leq 0.05$.

2.6. Ethical Considerations. This study was approved by the Ethics Committee of the Kermanshah University of Medical Sciences with the code of IR.KUMS.REC.1397.1049. The goals of the study were stated to the participants, and all of them were assured of the confidentiality of their demographic information and responses. Written informed consent to participation in the study was obtained from all participants. They were also given enough time to complete the questionnaires.

\section{Results}

More than half of the participants were male $(n=167$, $59.4 \%)$. The mean age of the students was $22.7 \pm 2.7$ years. The majority of the students $(n=143,50.9 \%)$ were in the age group 22-25 years and were from the school of medicine $(n=84,29.9 \%)$ (Table 1$)$.

The mean and standard deviation scores for time management skills, academic procrastination, and test anxiety were $42.0 \pm 6.3$ out of $70,46.4 \pm 7.7$ out of 64 , and $16.4 \pm 4.4$ out of 37 , respectively (Table 2 ).

Correlation analysis between the variables indicated a significantly negative correlation between time management skills and academic procrastination $(r=-0.487, P \leq 0.01)$. In addition, the total score of test anxiety was positively correlated with the academic procrastination score $(r=0.443$, $P \leq 0.01$ ) (Table 3 ).

The results of multivariate regression analysis showed that time management (beta $=-0.382$ ) and test anxiety $($ beta $=0.316)$ predicted academic procrastination. Time management and test anxiety explained $32.6 \%$ of the variation in academic procrastination (Table 4).

\section{Discussion}

The present study was conducted to determine the relationship of test anxiety and time management with academic procrastination among students of health professions in Iran.

The results showed that the mean score of test anxiety was at a moderate level and that of time management was slightly above the moderate level. The mean score of academic procrastination was above the average level. This finding was consistent with the findings of other studies $[2,6,39]$. In this regard, the results of Zhang et al. in Chinese students showed that $74 \%$ of them had procrastination in at least one academic assignment [2]. The findings of Atalayin et al. showed that half of dental students in Turkey suffered from procrastination [6]. The results of a study by Guo et al. in nursing students in China also revealed that students with low levels of self-efficacy had higher academic procrastination [39]. According to this evidence, procrastination is a challenge among students in many countries, including Iran. Many researchers have also emphasized that procrastination is a common and problematic phenomenon in students [3,40]. High levels of student procrastination in the current study may be related to
TABle 1: Demographic characteristics of students $(n=281)$.

\begin{tabular}{lcc}
\hline \multicolumn{2}{c}{ Variables } & $n(\%)$ \\
\hline \multirow{2}{*}{ Sex } & Male & $167(59.4)$ \\
& Female & $114(40.6)$ \\
\multirow{2}{*}{ Age (years) } & $18-21$ & $100(35.6)$ \\
& $22-25$ & $143(50.9)$ \\
\multirow{2}{*}{ Marital status } & $\geq 26$ & $38(13.5)$ \\
\hline \multirow{4}{*}{ School } & Single & $224(79.7)$ \\
& Married & $57(20.3)$ \\
\hline & Medical & $84(29.9)$ \\
& Dentistry & $24(8.5)$ \\
& Nursing and midwifery & $46(16.4)$ \\
& Paramedical & $76(27.0)$ \\
& Pharmacy & $24(8.5)$ \\
& Health & $13(4.8)$ \\
& Nutrition & $14(5.1)$ \\
\hline
\end{tabular}

TABLe 2: Mean and standard deviation of time management skill (and its subscales), academic procrastination, and test anxiety.

\begin{tabular}{lc}
\hline Variable & Mean (SD) \\
\hline Time management & $42.0(6.3)$ \\
Daily planning & $13.7(3.1)$ \\
Confidence in long-term planning & $28.3(4.06)$ \\
Academic procrastination & $46.4(7.7)$ \\
Test anxiety & $16.4(4.4)$ \\
\hline
\end{tabular}

Note. SD: standard deviation.

TABle 3: Correlation coefficients between study variables.

\begin{tabular}{lcc}
\hline Variables & \multicolumn{2}{c}{ Procrastination } \\
& $r$ & $P$ value \\
\hline Time management & -0.487 & $\leq 0.001$ \\
Test anxiety & 0.443 & $\leq 0.001$ \\
\hline
\end{tabular}

TABle 4: Summary of the regression models predicting academic procrastination as the dependent variable.

\begin{tabular}{lcccc}
\hline Model & $\beta$ & $t$ & $P$ value & $R^{2}$ \\
\hline Constant & - & 16.376 & $\leq 0.001$ & \\
Time management & -0.382 & -7.324 & $\leq 0.001$ & 32.6 \\
Test anxiety & 0.316 & 6.064 & $\leq 0.001$ & \\
\hline
\end{tabular}

" $t$ " is equivalent to a statistical value; " $\beta$ " is equivalent to the standard coefficient, and indicates which independent variable has an effect on the dependent variable; " $R$ " is the coefficient of determination.

several factors, such as lack of interest in the field of study, lack of motivation, and low self-esteem.

In the present study, a significantly negative relationship was found between time management skills and academic procrastination. In this regard, the results of one study showed that time management skills increased students' level of engagement and participation in the learning activities [26]. Ghiasvand et al. reported a significant correlation between time management and academic motivation [25]. Ping and Xiaochun showed that increased time management skills play an important role in reducing depression [24]. 
It is believed that time management skills are very important in the learning process because time management is a strategic skill and plays an important role in the achievement of goals in professional and academic fields [41]. But, procrastination is the opposite of time management and can lead to failure in students' education and life [42]. Therefore, enhancing the students' time management skills may play an important role in reducing the phenomenon of procrastination.

This study revealed that the test anxiety variable had a significantly positive correlation with academic procrastination $[18,20,43]$. The results of Balogun et al. showed a negative correlation between test anxiety and students' academic performance [43]. Therefore, psycho-educational interventions at the university level are necessary in this regard. Furthermore, Zhang and Henderson showed a negative and significant correlation between test anxiety and students' performance in the test [18]. The results of Steinmayr et al.'s study also showed that anxiety as an important component of test anxiety predicts changes in academic performance and subjective well-being [20].

Low levels of test preparation and lack of concentration are among the most important challenges of students in dealing with test anxiety. Delay in preparing for exams increases test anxiety in students. Studies have reported a negative correlation between academic performance and test anxiety $[18,20]$. Zhang et al. showed a significantly positive correlation between fear of failure and procrastination [2]. Moreover, the identification of the factors affecting the fear of failure and test anxiety plays a very important role in managing test anxiety in students. Most students are afraid of the final examinations. Therefore, evaluation of their performance in the learning process can be effective in reducing their anxiety. Anxiety is a psychological variable that has several causes. In the present study, the correlation between test anxiety and procrastination was investigated. In this regard, if instructors use formative assessments along with summative assessments, it can be effective in reducing students' exam anxiety because students are mostly concerned about grades in end-of-semester assessments. Therefore, professors can reduce students' test anxiety by assigning a part of the score to formative assessments.

4.1. Limitations. This research had three limitations. The nature of this study was cross-sectional and correlational. Therefore, it is impossible to determine the causal relationship between the variables. A self-report questionnaire was used to collect data. Hence, as it was not possible to verify the participants' answers, it may have affected the accuracy of the results. Numerous factors such as personal, social, psychological, and academic factors can affect academic procrastination, time management, and test anxiety, which were not examined in this study.

\section{Conclusion}

In the present study, the academic procrastination score in students of health professions was above the average level.
Time management was negatively associated with academic procrastination. Furthermore, a significantly positive correlation was found between test anxiety and academic procrastination. The results of regression analysis showed that test anxiety and time management predicted academic procrastination. Enhancing the time management skills and reducing test anxiety can play an important role in reducing academic procrastination. Evidence suggests that procrastination is a serious obstacle to students' academic achievement. Therefore, improving time management skills and taking measures to reduce test anxiety can reduce academic procrastination in students. Therefore, the findings of this study can be considered by educational planners and administrators in universities. Future studies are suggested to identify the social, psychological, and educational factors that influence academic procrastination, test anxiety, and time management.

\section{Data Availability}

The datasets used and analyzed during the present research are available from the corresponding author on reasonable request.

\section{Conflicts of Interest}

The authors declare that they have no conflicts of interest.

\section{Acknowledgments}

This study was drawn from a research project sponsored by Deputy of Research and Technology of KUMS. The authors thank all the students who participated in this study. The authors highly appreciate the Clinical Research Development Center of Imam Reza Hospital for its wise advice. This study was funded by the Kermanshah University of Medical Sciences, Kermanshah, Iran (No. 980230).

\section{References}

[1] S. Zacks and M. Hen, "Academic interventions for academic procrastination: a review of the literature," Journal of Prevention and Intervention in the Community, vol. 46 , no. 2 , pp. 117-130, 2018.

[2] Y. Zhang, S. Dong, W. Fang, X. Chai, J. Mei, and X. Fan, "Selfefficacy for self-regulation and fear of failure as mediators between self-esteem and academic procrastination among undergraduates in health professions," Advances in Health Sciences Education, vol. 23, no. 4, pp. 817-830, 2018.

[3] A. Gareau, M. Chamandy, K. Kljajic, and P. Gaudreau, "The detrimental effect of academic procrastination on subsequent grades: the mediating role of coping over and above past achievement and working memory capacity," Anxiety, Stress and Coping, vol. 32, no. 2, pp. 141-154, 2019.

[4] B. U. Özer, A. Demir, and J. R. Ferrari, "Exploring academic procrastination among Turkish students: possible gender differences in prevalence and reasons," The Journal of Social Psychology, vol. 149, no. 2, pp. 241-257, 2009.

[5] L. A. Rabin, J. Fogel, and K. E. Nutter-Upham, "Academic procrastination in college students: the role of self-reported 
executive function," Journal of Clinical and Experimental Neuropsychology, vol. 33, no. 3, pp. 344-357, 2011.

[6] C. Atalayin, M. Balkis, H. Tezel, and G. Kayrak, "Procrastination and predictor variables among a group of dental students in Turkey," Psychology Health and Medicine, vol. 23, no. 6, pp. 726-732, 2018.

[7] B. Madhan, C. S. Kumar, E. S. Naik, S. Panda, H. Gayathri, and A. K. Barik, "Trait procrastination among dental students in India and its influence on academic performance," Journal of Dental Education, vol. 76, no. 10, pp. 1393-1398, 2012.

[8] F. Mortazavi, S. S. Mortazavi, and R. Khosrorad, "Psychometric properties of the procrastination assessment scalestudent (PASS) in a student sample of sabzevar university of medical Sciences," Iranian Red Crescent Medical Journal, vol. 17, no. 9, Article ID e28328, 2015.

[9] W. K. Simpson and T. A. Pychyl, "In search of the arousal procrastinator: investigating the relation between procrastination, arousal-based personality traits and beliefs about procrastination motivations," Personality and Individual Differences, vol. 47, no. 8, pp. 906-911, 2009.

[10] N. Codina, R. Valenzuela, J. V. Pestana, and J. GonzalezConde, "Relations between student procrastination and teaching styles: autonomy-supportive and controlling," Frontiers in Psychology, vol. 9, p. 809, 2018.

[11] K. B. Klingsieck, "Procrastination," European Psychologist, vol. 18, no. 1, pp. 24-34, 2013.

[12] K. R. Kim and E. H. Seo, "The relationship between procrastination and academic performance: a meta-analysis," Personality and Individual Differences, vol. 82, pp. 26-33, 2015.

[13] M. Balkis and E. Duru, "Gender differences in the relationship between academic procrastination, satifaction with academic life and academic performance," Electronic Journal of Research in Educational Psychology, vol. 15, no. 1, pp. 105-125, 2017.

[14] F. M. Sirois, "Procrastination and stress: exploring the role of self-compassion," Self and Identity, vol. 13, no. 2, pp. 128-145, 2014.

[15] P. Steel, "The nature of procrastination: a meta-analytic and theoretical review of quintessential self-regulatory failure," Psychological Bulletin, vol. 133, no. 1, pp. 65-94, 2007.

[16] L. Visser, F. A. J. Korthagen, and J. Schoonenboom, "Differences in learning characteristics between students with high, average, and low levels of academic procrastination: students' views on factors influencing their learning," Frontiers in Psychology, vol. 9, p. 808, 2018.

[17] Z. Hyseni Duraku and L. Hoxha, "Self-esteem, study skills, self-concept, social support, psychological distress, and coping mechanism effects on test anxiety and academic performance," Health Psychology Open, vol. 5, no. 2, Article ID 2055102918799963, 2018.

[18] N. Zhang and C. N. R. Henderson, "Test anxiety and academic performance in chiropractic students," Journal of Chiropractic Education, vol. 28, no. 1, pp. 2-8, 2014.

[19] N. Custer, "Test anxiety and academic procrastination among prelicensure nursing students," Nursing Education Perspectives, vol. 39, no. 3, pp. 162-163, 2018.

[20] R. Steinmayr, J. Crede, N. McElvany, and L. Wirthwein, "Subjective well-being, test anxiety, academic achievement: testing for reciprocal effects," Frontiers in Psychology, vol. 6, p. 1994, 2016.

[21] W.-C. Wang, C.-H. Kao, T.-C. Huan, and C.-C. Wu, "Free time management contributes to better quality of life: a study of undergraduate students in Taiwan," Journal of Happiness Studies, vol. 12, no. 4, pp. 561-573, 2011.

[22] F. Bast, "Crux of time management for students," Resonance, vol. 21, no. 1, pp. 71-88, 2016.

[23] C. Amato, A. Pierro, A. Chirumbolo, and G. Pica, "Regulatory modes and time management: how locomotors and assessors plan and perceive time," International Journal of Psychology: Journal International de Psychologie, vol. 49, no. 3, pp. 192199, 2014.

[24] W. Ping and W. Xiaochun, "Effect of time management training on anxiety, depression, and sleep quality," Iranian Journal of Public Health, vol. 47, no. 12, p. 1822, 2018.

[25] A. Mohamadkhani Ghiasvand, M. Naderi, M. Zagheri Tafreshi, F. Ahmadi, and M. Hosseini, "Relationship between time management skills and anxiety and academic motivation of nursing students in Tehran," Electronic Physician, vol. 9, no. 1, pp. 3678-3684, 2017.

[26] J.-Y. Liu, Y.-H. Liu, and J.-P. Yang, "Impact of learning adaptability and time management disposition on study engagement among Chinese baccalaureate nursing students," Journal of Professional Nursing, vol. 30, no. 6, pp. 502-510, 2014.

[27] P. Limone, M. Sinatra, F. Ceglie, and L. Monacis, "Examining procrastination among university students through the lens of the self-regulated learning model," Behavioral Sciences, vol. 10 , no. 12 , p. $184,2020$.

[28] T. Hailikari, N. Katajavuori, and H. Asikainen, "Understanding procrastination: a case of a study skills course," Social Psychology of Education, vol. 24, no. 2, pp. 589-606, 2021.

[29] V. de Palo, L. Monacis, S. Miceli, M. Sinatra, and S. Di Nuovo, "Decisional procrastination in academic settings: the role of metacognitions and learning strategies," Frontiers in Psychology, vol. 8, p. 973, 2017.

[30] D. E. Gustavson and A. Miyake, "Academic procrastination and goal accomplishment: a combined experimental and individual differences investigation," Learning and Individual Differences, vol. 54, pp. 160-172, 2017.

[31] B. W. Tuckman, "The development and concurrent validity of the procrastination scale," Educational and Psychological Measurement, vol. 51, no. 2, pp. 473-480, 1991.

[32] B. W. Tuckman, "The effect of motivational scaffolding on procrastinators' distance learning outcomes," Computers and Education, vol. 49, no. 2, pp. 414-422, 2007.

[33] M. Moghadas Bayat, "Normalization of the tuckman procrastination assessment test for students," Dissertation at the Graduate Level, Islamic Azad University, Tehran, Iran, 2003.

[34] M. Trueman and J. Hartley, "A comparison between the timemanagement skills and academic performance of mature and traditional-entry university students," Higher Education, vol. 32, no. 2, pp. 199-215, 1996.

[35] K. Savari and A. Noori, "A Comparison of time management skills and achievement motivation of students with high and low academic performance," Journal of Educational Psychology, vol. 10, no. 31, pp. 109-124, 2014.

[36] I. G. Sarason, "Test anxiety and the self-disclosing coping model," Journal of Consulting and Clinical Psychology, vol. 43, no. 2, pp. 148-153, 1975.

[37] P. M. Raju, M. Mesfin, and E. Alia, "Test Anxiety Scale: reliability among Ethiopian students," Psychological Reports, vol. 107, no. 3, pp. 939-948, 2010.

[38] F. Rasouli Khorshidi, G. Sarami, H. Naderi, and A. A. Shojaei, "Modeling motivation in the relationship between test anxiety and academic procrastination with achievement," Education Strategies in Medical Sciences, vol. 12, no. 1, pp. 84-91, 2019. 
[39] M. Guo, X. Yin, C. Wang, L. Nie, and G. Wang, "Emotional intelligence a academic procrastination among junior college nursing students," Journal of Advanced Nursing, vol. 75, no. 11, pp. 2710-2718, 2019.

[40] B. A. Fernie, U. Y. Kopar, P. L. Fisher, and M. M. Spada, "Further development and testing of the metacognitive model of procrastination: self-reported academic performance," Journal of Affective Disorders, vol. 240, pp. 1-5, 2018.

[41] B. J. Claessens, W. Van Eerde, C. G. Rutte, and R. A. Roe, "A review of the time management literature," Personnel Review, 2007.

[42] C. A. Wolters, S. Won, and M. Hussain, "Examining the relations of time management and procrastination within a model of self-regulated learning," Metacognition and learning, vol. 12, no. 3, pp. 381-399, 2017.

[43] A. G. Balogun, S. K. Balogun, and C. V. Onyencho, "Test anxiety and academic performance among undergraduates: the moderating role of achievement motivation," Spanish Journal of Psychology, vol. 20, p. E14, 2017. 